\title{
Erratum to: Introduction: Perception Without Representation
}

\author{
Roberta Locatelli ${ }^{1}$ Keith A. Wilson ${ }^{2}$
}

Published online: 9 May 2017

(C) Springer Science+Business Media Dordrecht 2017

\section{Erratum to: Topoi \\ DOI 10.1007/s11245-017-9460-1}

In the original publication of the article, the M. G. F. Martin quotation under the section "Relational Views" cited as (2004: 93) is from p. 83 of his (1997) The reality of appearances, in Sainsbury M. (ed) Thought and ontology, Franco Angeli, Milano, pp. 81-106, reprinted on p. 93 of Byrne A., Logue H. (eds) (2009) Disjunctivism: contemporary readings, MIT Press, Cambridge, pp. 91-115.

The online version of the original article can be found under doi:10.1007/s11245-017-9460-1.

Keith A. Wilson

keith.wilson@glasgow.ac.uk

Roberta Locatelli

roberta.locatelli@uni-tuebingen.de

1 Department of Philosophy, Philosophisches Seminar and Philosophy of Neuroscience Group, Centre for Integrative Neuroscience, University of Tübingen, Otfried-Müller-Str. 25, 72076 Tübingen, Germany

2 Centre for the Study of Perceptual Experience, University of Glasgow, 69 Oakfield Avenue, Glasgow G12 8QQ, UK 